\title{
O DIREITO DO TRABALHO NA ERA DAS INCERTEZAS: DO PROCESSO CONSTITUINTE A JUDICIALIZAÇÃO
}

\author{
LABOR LAW IN THE AGE OF UNCERTAINTY: FROM THE CONSTITUENT PROCESS TO \\ JUDICIALIZATION
}

\begin{abstract}
Aimée Schneider
Doutoranda em Ciências Jurídicas e Sociais pelo Programa de Pós Graduação em Sociologia e Direito pela Universidade Federal Fluminense. E-mail: schneider_aimee@hotmail.com
\end{abstract}

Tayssa Botelho

Doutoranda em Ciências Jurídicas e Sociais pelo Programa de Pós-Graduação em Sociologia e Direito pela Universidade Federal Fluminense.Professora na Universidade Cândido Mendes.

E-mail: tayssabotelho@yahoo.com.br

Recebido em: 11/09/2018

Aprovado em: 27/06/2019

RESUMO: O presente artigo almeja proceder ao contraste entre a abordagem empregada ao longo do período de atividade da Assembleia Nacional Constituinte de 1987-88 para as questões atinentes aos direitos do trabalhador e os efeitos concretos das recentes mudanças trabalhistas. Tal exame se alinha à necessidade, sociopoliticamente instaurada, de revisão dos trabalhos constituintes à luz do trigésimo aniversário da Constituição da República Federativa do Brasil de 1988, completos no próximo dia 05 de outubro. A partir desta análise, busca-se investigar o modo como o constitucionalismo, tradicionalmente apresentado como um mecanismo garantidor da previsibilidade nas relações trabalhistas, hoje se mostra incapaz de processar o ritmo das mudanças infligidas a estas pelos procedimentos de reestruturação empresarial. Face a tal conjuntura, o Poder Judiciário se revela como um agente de políticas diretas e indiretas, conformando-se como uma arena, não obstante contenciosa, onde os trabalhadores poderão mobilizar seus direitos, em um verdadeiro exercício de cidadania.

Palavras-chave: Constitucionalismo. Direito do Trabalho. Terceirização. Poder Judiciário.

ABSTRACT: The following article focus on the contrast between the approach towards the working class demands in the works of the National Constituent Assembly of 1987-88 and the recent changes in the labor law landscape. Such an evaluation is aligned with the sociopolitical need to review the constituent procedures in the light of the thirtieth birthday, on the next 5th of October, of the Constitution of the Federative Republic of Brazil; it also meets the purpose of providing the tools needed to analyze the way in which constitutionalism, once presented as a mechanism able to provide working relationships with a degree of predictability, is now unable to cope with the fast-paced changes brought by corporate restructuring processes such as the outsorcing of services. That has been the atmosphere in which Judicial Power has risen as a vessel 
for both direct and indirect policies - a quarrel-filled arena where workers may have the chance to seek a concrete outcome for their rights and citizenship.

Keywords: Constitutionalism. Labor Law. Outsorcing. Judicial Power.

SUMÁRIO: Introdução; 1 A Constitucionalização dos Direitos Trabalhistas: da Previsibilidade à Instabilidade; 2 Os Trabalhadores no Processo Constituinte de 1987-1988 231; 3 As Mudanças do Trabalho no Brasil das Instabilidades: o Fenômeno da Terceirização; $3.1 \mathrm{O}$ que significa terceirizar; 3.2 As tendências da terceirização no Brasil; 4 Os Trabalhadores nos Processos Judiciais: o Judiciário como lugar de Mobilização dos Direitos Trabalhistas; Considerações Finais; Referências Bibliográficas.

\section{INTRODUÇÃO}

A reflexão acerca dos 30 anos da Constituição Federal de 1988, haja vista a relevância histórica dessa data simbólica, enseja questionamento e balanços a partir do entrelace entre o ontem $e$ o hoje. O objetivo desta pesquisa perpassa às discussões sediadas na Assembleia Nacional Constituinte (doravante ANC) de 1987-88 com a finalidade de desvelar a dupla importância histórica e atual - dos direitos trabalhistas. Entender a trajetória de formação da Carta Magna demanda uma análise que envolve, a um só tempo, o momento constituinte brasileiro e a forma como a discussão do Direito do Trabalho tem-se colocado nesse momento, em razão dos seus reflexos continuarem sendo projetados para o debate político e jurídico da atualidade.

A metodologia que viabilizou essa análise tem caráter historiográfico na medida em que mantém uma perspectiva da compreensão das Ciências não condicionada apenas a dogmas, mas sim a premissas permanentemente questionáveis, viabilizando, com isso, uma análise crítica do Direito. Considera-se que a norma jurídica é um produto do momento históricoem que concebida e, nesse aspecto, a ANC de 1987-88 é um desdobramento da redemocratização brasileira após anos de ditadura. Nesta esfera, será adotado, como referencial metodológico de análise, o mapeamento de duas etapas: os debates e as propostas, ocorridos durante a Constituinte, acerca dos direitos do trabalhador e, em seguida, a análise do que seriam tais direitos, pensados a partir da atual conjuntura trabalhista.

Deste modo, para que se possa construir um quadro teórico, o estudo ora apresentado se apoia em uma pesquisa documental, de forma a demonstrar a essencialidade e atualidade do tema proposto, e parte de uma abordagem interdisciplinar, notadamente através da interseção entre História e Direito: "[a] interdisciplinaridade rompe com o paradigma hegemônico da pesquisa positivista: ordem, redução e pensamento simplificador" (MADEIRA, 2012, p. 200). Sob esse prisma, a interdisciplinaridade envolve paradigmas não necessariamente de uma nova ciência, mas de novas abordagens de métodos científicos, promovendo uma multidisciplinaridade solidária (MADEIRA, 2012, p. 208). Assim é que se busca incentivar a adoção de um prisma por meio do qual a Carta Constitucional de 1988 seja vista não como um simples texto mecânico, composto por alíneas, parágrafos e artigos, mas sim algo pulsante, vivo. À luz de tal propósito, a formulação de um pensamento ahistórico em torno da redação do diploma constitucional tenderia à incompletude.

No entrelace com tais bases constitucionais, a questão trabalhista brasileira será examinada a partir daqueles que se revelam como seus nortes e agentes de teor mais contemporâneo. A relação dos trabalhadores com o Poder Judiciário em face de estruturas nas quais seus direitos se deparam com o risco de expressiva relativização - notadamente, por meio de serviços terceirizados - será, assim, abordada, buscando analisar como a própria remodelação deste Poder constituído pode contribuir para a maior participação política do trabalhador, em conjunto 
com a própria democratização do acesso à Justiça. As possíveis maneiras de se atingir tais objetivos, bem como as dificuldades concretas que se impõem, serão escrutinizados a seguir.

\section{A CONSTITUCIONALIZAÇÃO DOS DIREITOS TRABALHISTAS: DA PREVISIBILIDADE À INSTABILIDADE}

Segundo Boaventura de Sousa Santos (1990), a racionalidade cartesiana fez do projeto da modernidade um terreno fértil para polarizações dicotômicas de difícil mediação, todas baseadas no binômio formalidade/informalidade.

$\mathrm{O}$ século XX nasceu da resistência ao formalismo do direito napoleônico e da teoria política liberal. A reação assumiu dois caminhos: um antiformalista - a revolução - e um formalista - o reformismo. Este último tornou-se o modelo hegemônico e, sob o aspecto político, foi cristalizado no Estado Providência:

A precedência dada ao reformismo foi acentuando os traços formalistas deste. Em primeiro lugar, porque a regulamentação extensiva e intensiva das relações sociais se fez no marco do direito estatal formal; em segundo lugar, porque, decorrente dessa regulamentação em permanente crescimento, o Estado expandiu enormemente o seu aparelho burocrático, ele próprio dominado por processos formais de decisão; em terceiro lugar, porque as teorias dominantes da representação política converteram os partidos e de algum modo também os sindicatos em organizações formais e exclusivas dos interesses setoriais, recusando todas as alternativas informais de agregação de interesses, tal como a democracia direta e de base ou os direitos não estatais (SANTOS, 1990, p.15).

Com a prevalência do reformismo, o campo econômico também se reestruturou, dando origem à fase do capitalismo organizado, marcado pelo regime de produção fordista. Nesta nova etapa, a positivação e a regulação de direitos fixou parâmetros jurídico-sociais e expectativas sobre justiça, equidade e democracia (SANTOS, 2009).

Durante a fase organizada, o Direito do Trabalho assumiu um caráter coletivo, procurou uniformizar os estatutos sociais e apoiou-se na efetividade do emprego. O trabalhador mantinha um vínculo de subordinação por tempo indeterminado com a empresa na qual laborava. Ele contava com estabilidade salarial, temporal e empregatícia.

O capitalismo organizado, distinguindo-se do capitalismo liberal, na vã esperança de conferir segurança às relações trabalhistas, tratou de estabelecer padrões jurídicos e disseminar expectativas sobre a justiça. ${ }^{1}$ Assumindo uma feição coletiva e baseando-se na efetividade das relações entre empregado e empregador, o Direito do Trabalho uniformizou estatutos sociais.

No Brasil, os estatutos trabalhistas alcançaram o topo do ordenamento jurídico mediante o processo constituinte de 1987-1988. A elevação dos direitos dos trabalhadores à categoria de direitos fundamentais foi fruto da tentativa estatal de regular os riscos provenientes da atividade operária, criando padrões de segurança e previsibilidade ontológica e jurídica para as relações trabalhistas (SANTOS, 2009).

Entretanto, toda a estrutura do capitalismo organizado vem ruindo. O Estado-Providência, o modo de produção fordista, o contrato social e todos os modelos baseados no formalismo reformista entraram em uma crise que se aprofundou ano após ano. Dela, nasceu o movimento

\footnotetext{
${ }^{1}$ Graça Druck e Annie Thébaud-Mony (2007, p. 24) afirmam que a precariedade que marcou o capitalismo industrial e o processo de formação do trabalho assalariado durante o século XIX foi superada nos países centrais graças às conquistas do movimento operário, dentre as quais a principal foi a ampliação do papel do estado como regulador do mercado de trabalho. No entanto, os avanços não teriam impedido a permanência do trabalho precarizado em países periféricos.
} 
informalista que, no plano político, é representado pela decadência do Estado de Bem-Estar e, no plano econômico, pelo capitalismo desorganizado (SANTOS, B. S., 1990, p.15-16).

A nova fase é marcada por uma desregulação global da vida social, política e econômica. Nenhum dos princípios de regulação - seja o mercado, o Estado ou a comunidade - consegue garantir, por si só, a regulação social ante a volatilidade onipresente. Paradoxalmente, o modelo que prometia aumentar material e institucionalmente o número de escolhas acarreta a diminuição da capacidade de escolher. Como resultado:

As sociedades capitalistas avançadas parecem bloqueadas, condenadas a viver do excesso irracional do cumprimento do projeto da modernidade e a racionalizar num processo de esquecimento ou de autoflagelação o déficit vital das promessas incumpridas. (SANTOS, B. S., 1997, p.89-90).

Os trabalhadores, antes forjados sob uma série de padrões ideais, são, agora, submetidos a um contexto novo marcado pela despadronização. A ausência de normas reguladoras das condições de trabalho passa a conviver com a flexibilização do tempo de trabalho e dos salários, com o desemprego, com a atenuação do contrato de trabalho e com a perda da dimensão coletiva. De penhor da estabilidade, o trabalho constitui-se agente de exclusão e perde a capacidade de gerar coesão social, um quadro que nem mesmo as mudanças na legislação tem conseguido reverter.

O que outrora era construído como segurança tornou-se apenas, risco.

\section{OS TRABALHADORES NO PROCESSO CONSTITUINTE DE 1987-1988}

Em 15 de novembro de 1986, ocorreram as eleições dos Deputados Federais e dos Senadores, os quais não somente exerceram as funções legislativas comuns, como também compuseram a Assembleia convocada. No dia $1^{\circ}$ de fevereiro de 1987, a ANC reuniu-se no Congresso Nacional, sendo composta por 559 membros, somando 487 Deputados Federais e 49 Senadores eleitos em 1986; para além desses, outros 23 Senadores, conhecidos como biônicos que representavam a parcela remanescente das eleições indiretas, ocorridas em 1982 e cujos mandatos só se encerrariam em 1990.

A instalação da ANC data de $1^{\circ}$ de fevereiro de 1987 e, segundo o seu Regimento Interno, o processo se estruturaria nas seguintes etapas:a elaboração deveria começar pelas Subcomissões, que entregariam seus trabalhos às Comissões e, estas, à Comissão de Sistematização que, por sua vez, entregaria um Projeto de Constituição ao Plenário,que viria a ser votado emdois turnos (BRASIL, 1987c). Em termos práticos, seriam quatro fases, encadeadas da seguinte forma: 24 Subcomissões $\rightarrow 08$ Comissões $\rightarrow$ Comissão de Sistematização $\rightarrow$ Plenário.

Cada Comissão teria 63 titulares e o mesmo número de suplentes; as Subcomissões, por volta de 21 titulares e 21 suplentes; e a Comissão de Sistematização, por sua vez, 49 titulares e 49 suplentes, mais os 08 Presidentes das Comissões e os 32 Relatores das Subcomissões e Comissões. Em cada uma destas instâncias deveria haver um Presidente, que designaria o Relator, e dois VicePresidentes. Todos os Constituintes seriam titulares de uma Comissão e suplentes de outra. Todavia, muito embora as tratativas em torno da composição de cada uma das Comissões visassem à manutenção da proporcionalidade representativa entre os partidos, cabe notar que apenas quatro deles possuíam membros em número suficiente para ocupar pelo menos uma vaga em todas as Comissões e Subcomissões: PMDB, PFL, PDS e PDT.No âmbito dos direitos trabalhistas, a temática foi elaborada pela Subcomissão dos Direitos dos Trabalhadores e Servidores Públicos, que encaminharia o seu anteprojeto à Comissão da Ordem Social.

Convém apontar que antes mesmo do início dos trabalhos da Constituinte já existiam reivindicações da sociedade brasileira endereçadas à ANC. O Congresso Nacional recebeu, desde o ano de 1986, correspondências de todo o país, fosse de forma individual, fosse através de 
entidades sociais. Entre março daquele ano e julho de 1987, o ente estatal, através da Comissão de Constituição e Justiça do Senado, lançou o plano "Diga Gente e Projeto Constituição", com o intuito de que os cidadãos expressassem suas sugestões para a vindoura Lei Maior.Cinco milhões de formulários foram distribuídos e disponibilizados nas agências dos Correios do Brasil, o qual os encaminhava, sem custos, para o Senado Federal, que recebeu um total de 72.719 respostas (BACKES; AZEVEDO, 2008, p. 73). Aparentemente, as iniciativas individualizadas não possuíam vínculo institucional, sendo mensagens pessoais enviadas às autoridades políticas.Ao pesquisar os termos "direitos dos trabalhadores", "trabalhador" e "trabalho", foram encontrados respectivamente 103, 5.942 e 12.296registros, e as sugestões, no geral, conclamavam a ampliação dos Direitos dos Trabalhadores - não apenas urbano, mas em inúmeras propostas há o destaque para os trabalhadores rurais.

Propostas ilustrativas são aquelas que defendem: a) "completa garantia das liberdades democráticas dos direitos dos trabalhadores (...) com direito de greve e de manifestação pública" Rubens Silva Pinheiro, formulário 574, UF: MA (BRASIL, 1987d); b) "a constituinte melhore a vida do trabalhador, porque os interesses e direitos dos trabalhadores nunca foram considerados" Dorivaldo Borges Teixeira, formulário 002, UF: BA (BRASIL, 1987d); e c) "que os direitos dos trabalhadores sejam assegurados e ampliados" José Ailton Neves de Oliveira, formulário 293, UF: CE (BRASIL, 1987d). Apesar de serem em um número menor, também existem propostas no sentido de limitar e diminuir tais direitos. A título de exemplo, cita-se a sugestão de Amiliar Fernandes da Silva Neto que defende uma revisão das leis trabalhistas com o intuito "de ampliar os deveres e limitar os direitos dos trabalhadores, uma vez que eles encontram muito amparo legal e têm pouca responsabilidade no tocante ao cumprimento de suas obrigações". Formulário 639, UF: PR (BRASIL, 1987d).Os textos vinham cheios de expectativas, e a vida social se projetava neles. A escrita não era neutra e, em inúmeros casos, os manifestantes se referiam a situações próprias para exemplificar questões da órbita geral, expondo suas preferências e valores que, por vezes, eram compartilhados por outros, em sugestões diversas.

Com a instalação da ANC, os próprios parlamentaresapresentaram sugestões totalizando a soma de 12.000 propostas sobre os mais diversos assuntos.Atinentes às questões trabalhistas, a busca resultou em1449, 822 e 552 registros para "direitos dos trabalhadores", "trabalhador" e "trabalho", respectivamente. Em sua maioria, textos se apresentam com redações mais genéricasse comparados com as propostas populares, tais como a criação de normas protetivas dos trabalhadores. A temática rural também é recorrente(BRASIL, 1987a).

A sociedade civil também se manifestava por diferentes formas: envio de sugestões por entidades sociais, audiências públicas, cartas pessoais e emendas populares.O mecanismo de Projetos de Emendas Populares (PEP), por exemplo, exerceu grande influência na organização e na mobilização social, tornando-se um canal aberto para versar sobre diversos temas: foram apresentadas 122 PEP que obtiveram um "total de 12.277.423 assinaturas.Considerando que cada eleitor pode subscrever até três emendas, entre $6 \%$ e $18 \%$ dos eleitores da época assinaram alguma emenda" (BRANDÃO, 2011, p. 79). No tocante aos Direitos dos Trabalhadores, quatro versaram diretamente sobre o assunto, quais sejam: PEP 009, PEP 054, PEP 066 e PEP 074 (BRASIL, 1987b).

O número de assinaturas da PEP 009 foi de 30.240. Dentre as proposições, destaca-se a ideia de que o que toda organização da ordem econômica deve "fomentar-se no reconhecimento da primazia do trabalho sobre o capital. A Lei assegurará a prioridade de remuneração do trabalho, atendidas as necessidades básicas do trabalhador (...)" (BRASIL, 1987b, p. 12). Por sua vez, o número de assinaturas daPEP 054 foi de 743.718. Alguns dos direitos pleiteados foram o salário mínimo, o salário família, a duração máxima de jornada diária, o repouso remunerado, o fundo de garantia e a greve (BRASIL, 1987b, pp. 54-55). Já a PEP, que atingiu272.624assinaturas, estabelecia que a Justiça do Trabalho poderia normatizar situações que requeiram tratamento especial ou que não estejam previstas. $O$ texto também afirmava que não se podia admitir "o 
estabelecimento de normas constitucional, que certamente alcançarão o século XXI, preservandose o grau de miséria e abandono da classe trabalhadora". A proposta fixava também que os artigos previstos independeriam de lei, evitando-se, assim, as "situações em que a previsão constitucional permanece ao longo de décadas sem regulamentação"2 (BRASIL, 1987b, pp. 65-67). Por fim, a PEP 074, que obteve 13.549 assinaturas, ${ }^{3}$ além dedefender os direitos acima expostos, resguardava os direitos dos trabalhadores de criarem comissões nos locais de trabalho, liberdade e autonomia sindical (BRASIL, 1987b, p. 74).

O Senador Afonso Arinos (PFL - RJ), Presidente da Comissão de Sistematização da Constituinte, na apresentação do documento das emendas populares, resume:

Acentuemos, finalmente, que nesta primeira experiência brasileira, a par dos efeitos gerais de fortalecimento da legitimidade, de identificação das principais aspirações da população, de valorização de ideias e não apenas de pessoas, impressionam a amplitude e a espontaneidade de sua efetivação. Em poucos meses, nada menos do que cerca de 12 milhões de assinaturas foram recolhidas por entidades de natureza diversa, num processo difícil de mobilização popular, superando-se distâncias físicas e culturais, com resultados inegavelmente positivos para a educação política de nosso povo.

Apenas por este aspecto inovador e promissor, a Constituinte brasileira de 1987 já marcou seu lugar nos processos contemporâneos de elaboração constitucional.(BRASIL, 1987b, p. 08).

Daí que a participação popular permeou a ANC de viés popular e democrático inéditos no país.Cabe sublinhar, no entanto, que ao enfatizar o papel popular não se está deixando de reconhecer a importância da dinâmica institucional da ANC de 1987-88, posto que a própria Constituinte foi formada majoritariamente por partidos e parlamentares identificados com os interesses dos empresários (PILATTI, 2008)

A Subcomissão temática que recebeu maior número de propostas populares foi a dos Direitos dos Trabalhadores e Servidores Públicos com 1.418 (MICHILES et. al., 1989). Tal número condiz com a ampla participação de entidades de classe e representantes de categorias voltados para as discussões acerca dos direitos trabalhistas - além desses, dois representantes do Estado falaram nas audiências públicas: o Ministro do Trabalho e o Ministro da Administração. A análise desses discursos revela nuances importantes sobre o conteúdo e a articulação das propostas populares, oferecendo, ainda, uma perspectiva do processo de incorporação dos direitos sociais e do pluralismo no texto constitucional.

Dentre as várias reivindicações encaminhadas pelos trabalhadores, a autonomia no ambiente de trabalho e a liberdade sindical representam as demandas mais urgentes. A liberdade de organização e de gestão seria um modo de se aplicar a Constituição, na medida em que tornaria o texto constitucional mais próximo da realidade e das práticas cotidianas. O depoimento do representante do Departamento Intersindical de Estatística e Estudos Socioeconômicos (DIEESE), Joel Alves de Oliveira, é significativo no que tange às reivindicações dos trabalhadores que, para ele, os principais tópicos são: a redução da jornada de trabalho, a representação dos trabalhadores nos locais de trabalho, e a garantia no emprego. Alertou que se "pararmos para verificar qual a

\footnotetext{
${ }^{2}$ Confirmando o ponto aqui exposto, com relação à Constituição Federal de 1988, a jurista e política Anna Maria Rattes elucidou que, até o ano de 2009, “66 dos 250 artigos aprovados não foram regulamentados e por isso ficam sem aplicação prática. Ou seja: 26,4\% do texto existem apenas no papel” (RATTES, 2009, p. 28)

${ }^{3}$ Apesar de o Regimento Interno da ANC estabelecer, em seu artigo 24, que a emenda popular deveria ser subscrita por pelo menos 30.000 (trinta mil) eleitores brasileiros, o sucesso da campanha de coleta de assinaturas fez com que os Constituintes decidissem que todas as 122 emendas fossem apresentadas no Plenário. Chegou-se ao ponto de 39 delas, que não conseguiram cumprir as exigências regimentais, serem subscritas por Constituinte, garantindo, assim, a sua apreciação.
} 
evolução dos direitos dos trabalhadores, vamos observar que nas questões fundamentais ainda há muito o que se conquistar". 4

Em outro momento, o Presidente da Central Única dos Trabalhadores, Jair Antônio Meneghelli, tratou da liberdade e autonomia sindical. A liberdade de organização dos trabalhadores seria a chave para que a democracia fosse vivenciada de fato. A experiência democrática é evocada para que se estabeleçam relações baseadas nas liberdades ampliadas e em uma menor intervenção estatal. Nesse sentido, Meneghelli afirma acreditar na capacidade de "organização da classe trabalhadora brasileira, mas nos deem liberdade de autonomia sindical, nos deem a possibilidade de organizarmos como bem entendermos. Aí, eu não terei dúvidas de que conseguiremos conquistar as nossas reivindicações". 5

Os direitos trabalhistas foram reivindicados em todas as instâncias, sobretudo as populares, de modo que a constitucionalização desses direitos, elevando-os a categoria de Direito Fundamental, permitiu novas maneiras de se pensar o Direito do Trabalho. A sua valorização passou a ser atrelada na ordem constitucional à dignidade da pessoa humana e à justiça social. A ampliação dos direitos sociais e do trabalho, portanto, no âmbito constitucional foi influenciada pela participação da sociedade no processo constituinte.

Projetando-se a análise para o momento atual, é de se questionar acercadas mudanças trazidas ao panorama constitucional por meio das reformas já engendradas - dentre as alterações mais recentes que acenam para a retirada de direitos, destaca-se a reforma trabalhista, delineada na Consolidação das Leis do Trabalho (CLT) - e daquelas que poderiam advir do panorama político corrente, desbotando, com o passar dos anos e dos capítulos da ainda jovem democracia, os direitos e as garantias plasmadas no texto da Carta Magna de 1988.

\section{AS MUDANÇAS DO TRABALHO NO BRASIL DAS INSTABILIDADES: O FENÔMENO DA TERCEIRIZAÇÃO}

\subsection{O que significa terceirizar}

São muitos os nomes usados para designar as novas formas de organização empresarial e trabalhista na fase do Capitalismo desorganizado. Aqui, fala-se, especificamente, da modalidade de reestruturação baseada na delegação de atividades antes desenvolvidas dentro das fronteiras empresariais. O modelo recebe nomenclaturas diversas: subcontratação, reconcentração, focalização, desverticalização, descentralização, exteriorização do emprego, parceria, tercearização, ou, o mais famoso deles, terceirização.

"Terceirizar" é um neologismo advindo do acréscimo do sufixo "izar" ao vocábulo "terceiro", que vem do latim tertiariu e pode significar "pessoa estranha a uma relação ou ordenação jurídica", ou "intercessor, medianeiro, intermediário" (RAMOS, 2001, p. 48).

O significado de "terceirização" varia conforme o campo de observação - Direito, Sociologia, Economia, Administração - cada qual operando com lógicas próprias. E, mesmo dentro de cada campo, surgem numerosas definições. Todavia, há elementos centrais que todas eles parecem compartilhar, como a ideia de transferência de atividades empresariais e responsabilidades para um terceiro, bem como a correlação com a flexibilidade produtiva e trabalhista.

$\mathrm{Na}$ Ciência da Administração, grande responsável pela produção e reprodução de conceitos relacionados ao tema, o termo representa a técnica de gestão empresarial baseada na concentração de recursos em competências consideradas essenciais e na delegação das demais

\footnotetext{
${ }^{4}$ Ata da $18^{a}$ reunião da Subcomissão dos Direitos dos Trabalhadores e Servidores Públicos,em 06 de maio de 1987, p. 229.

${ }^{5}$ Ata da $20^{a}$ reunião da Subcomissão dos Direitos dos Trabalhadores e Servidores Públicos, em 07 de maio de 1987, p. 262.
} 
atividades para organizações especializadas. Nas palavras de Ciro Pereira da Silva (1997, p.30), a terceirização constitui:

[...] transferência de atividade para fornecedores especializados, detentores de tecnologia própria e moderna, que tenham essa atividade terceirizada como sua atividade-fim, liberando a tomadora para concentrar seus esforços gerenciais em seu negócio principal, preservando e evoluindo em qualidade e produtividade, reduzindo custos e gerando competitividade.

Terceirizar não é um simples meio de reduzir custos. Trata-se de um modelo organizacional inserido em uma estratégia maior de diferenciação de produtos e mercados ${ }^{6}$. A definição de Fontanella et. tal reforça a ideia de que a organização terceiriza para se concentrar na alma do negócio, isto é, naquilo que seria o seu diferencial competitivo. A prática altera a estrutura empresarial, porquanto consiste:

[...] na aquisição de bens e/ou serviços especializados, de forma sistemática e intensiva, para serem integrados na condição de atividade meio à atividade fim da empresa compradora, permitindo a concentração de energia em sua real vocação, com o intuito de potencializar ganhos em qualidade e produtividade (FONTANELLA et. tal, 1994, p.19).

Rodrigo Carelli (2003) explica que os conceitos extraídos do campo da Administração apoiam-se em pontos comuns: a transferência de atividades a terceiros, a especialização das contratadas, o foco na atividade principal das contratantes, os jogos de parceria. Para o autor, "terceirização" é um termo brasileiro usado para indicar que se transfere a um terceiro, a um outro, uma atividade que até então era de responsabilidade exclusiva da empresa contratante.

Embora o termo "terceirização" seja recente, a técnica de gestão é antiga. Esteve presente desde a Revolução Industrial, perpassando todo o período de ascensão do regime fordista, principalmente no setor de extração de carvão e nos serviços portuários. Despontou durante a Segunda Guerra Mundial, quando as indústrias bélicas norte-americanas passaram a delegar algumas de suas atividades, a fim de ampliar a sua capacidade produtiva. Com o final da guerra e o aumento da produção, a ideia consolidou-se.

Mas pode-se dizer que o fenômeno também é novo. Ele se tem intensificado ao longo das últimas décadas, tornando-se um dos maiores instrumentos de flexibilização da produção. A terceirização tem deixado a periferia e passado a ocupar o epicentro dos modelos de organização empresarial.

O modelo faz sucesso, porque se adapta perfeitamente às necessidades de flexibilização produtiva. Ele garante liberdade de gestão, principalmente com a transferência das responsabilidades que acompanham as atividades delegadas. Leiria (1992, p.53) afirma que a terceirização diminui o desperdício, aumenta a qualidade dos produtos, libera pessoal para outras atividades fundamentais, garante o sinergismo nas atividades fins, amplia a especialização, aperfeiçoa serviços, permite melhor administração do tempo da empresa, agiliza decisões, aumenta o número de empresas e empregos disponíveis no mercado, especialmente, daqueles especializados. A terceirização acarreta, portanto, a racionalização de recursos através da compilação da estrutura e das responsabilidades da empresa.

\footnotetext{
${ }^{6}$ De acordo com Henry Mintzberg e James Brian Quinn (2001), as estratégias empresariais são, ao mesmo tempo, deliberadas e emergentes. Os empresários tomam decisões e, concomitantemente, reagem às decisões alheias. Dessas operações individuais e interativas nascem os padrões estratégicos.

Os autores dividem em cinco grupos os atuais padrões estratégicos das empresas, nascidos em meados do século XX: 1. Localização da essência do negócio; 2. Distinção da essência do negócio; 3. Desenvolvimento da essência do negócio; 4. Extensão da essência do negócio; 5. Reconfiguração da essência do negócio.
}

Revista de Direito Brasileira | Florianópolis, SC | v. 23 | n. 9 | p.228-248 |Mai./Ago. 2019 
Mas Leiria (1992, p.53) também chama a atenção para as repercussões negativas: demissões e instabilidades no trabalho, custos de implementação e das mudanças na estrutura empresarial, aumento da percepção de riscos, dificuldades com o controle e fiscalização dos parceiros, problemas na relação com sindicatos, falta de parâmetros para definir os preços nas contratações iniciais e aumento na dependência de terceiros.

Indo mais além, Graça Druck e Annie Thébaud-Mony (2007) afirmam que a liberdade de gestão que acompanha a terceirização é a própria liberdade do capital para gerir e dominar a força de trabalho quase sem limites. Como um mecanismo central da flexibilidade, a terceirização também representa um dos maiores instrumentos de precarização do trabalho humano.

Sob a ótica do Direito, que trabalha com o binômio lícito-ilícito, a terceirização adquire a natureza jurídica de contrato comercial entre empresas (CARELLI, 2004, p. 45). É tratada como um tema do Direito Civil que repercute no Direito do Trabalho de forma reflexa. Por esse motivo, a delegação de atividades para organizações especializadas não se confunde com o mero fornecimento de trabalhadores de uma empresa para outra, a chamada intermediação da mão de obra, que é considerada ilícita na medida em que mercantiliza o trabalho humano.

O liame entre as duas práticas é o agente que organiza, dirige e controla o trabalho, isto é, aquele a quem o trabalhador está subordinado. Se a empresa contratada não é especializada e não detém materiais ou técnicas específicas para prestar os serviços, antes funciona apenas como uma extensão das atividades permanentes da contratante, há intermediação de mão de obra e não terceirização. Uma faz prevalecer o elemento humano e a outra, o conhecimento técnico especializado. O problema é que os limites nem sempre são nítidos.

A terceirização está em franca expansão. Dinâmica, ela se propaga para outros setores da economia ao passo que se recria em novas modalidades. Cresce a delegação de atividades para trabalhadores autônomos e para cooperativas. A especialização de atividades aprofunda-se e adquire novos níveis com a quarterização, que ocorre quando os serviços delegados a terceiros são novamente transferidos para outros agentes. Surgem as franquias, uma parceria empresarial na qual a empresa franqueadora vende o conhecimento e o padrão da operação do seu negócio para a franqueada. E, finalmente, a Administração Pública, marcada pelo projeto gerencialista, adere ao modelo e passa a delegar serviços públicos.

\subsection{As tendências da terceirização no Brasil}

A terceirização no mercado brasileiro tem uma longa história cuja origem remonta ao final da década de 1960. Inicialmente, as relações trilaterais foram incentivadas dentro da própria Administração Pública, conforme se observa nas primeiras leis que abordam a delegação de serviços a terceiros. Posteriormente, elas se estenderam para o setor privado, sempre atraindo trabalhadores da base da pirâmide social. O movimento adquiriu relevância na década de 1990, coincidindo com os processos de abertura comercial e desregulamentação dos contratos de trabalho. Obteve um crescimento contido até 1994, quando foi impulsionado pela estabilização monetária (POCHMANN, 2014).

Em pesquisa realizada na indústria petroquímica da Bahia no ano de 1995, Graça Druck (DRUCK e FRANCO, 2008) distinguiu algumas das espécies de terceirização presentes no cenário nacional. Eram elas: subcontratação do trabalho doméstico ou domiciliar na qualidade de autônomo, modalidade comum aos setores mais tradicionais da indústria; redes de empresas fornecedoras de componentes e peças, encontradas principalmente na indústria automobilística; subcontratação de serviços periféricos ou de apoio; subcontratação de empresas ou trabalhadores autônomos nas áreas produtivas e nucleares, como na atividade de manutenção; quarterização, uma cascata de subcontratações.

Desde aquele ano, a terceirização expandiu-se tanto no setor público, quanto no privado, difundindo-se por todos os âmbitos da estrutura empresarial, inclusive os que antes eram 
considerados nucleares. Novas modalidades têm surgido, dentre as quais se destacam o trabalho domiciliar, agora internacionalizado, o microempreendedorismo individual ${ }^{7}$, o cooperativismo e as franquias.

Os modelos recentes priorizam a terceirização realizada mediante trabalho por conta própria. Eles incentivam o processo de assalariamento disfarçado, no qual o trabalhador redefine a sua personalidade jurídica e assume os encargos pelo trabalho realizado. O poder constitutivo de uma simples mudança do nomem juris é capaz de pôr empresas contratantes e trabalhadores terceirizados no mesmo patamar jurídico.

De acordo com a pesquisa elaborada pela Central Única dos Trabalhadores (CUT) em parceria com o Departamento Intersindical de Estatísticas e Estudos Socioeconômicos (2014), utilizando a base de dados da Relação Anual de Informações Sociais (RAIS) de 2013, os trabalhadores terceirizados compõem $26,8 \%$ do mercado formal de trabalho no Brasil, perfazendo um total de 12,7 milhões de assalariados, conforme se verifica na tabela abaixo. Este número seria ainda maior caso fossem considerados os trabalhadores informais.

TABELA 1 - Distribuição dos trabalhadores em setores tipicamente terceirizados e tipicamente contratantes

\begin{tabular}{|c|c|c|}
\hline \multirow{2}{*}{ Setores } & \multicolumn{2}{|c|}{2013} \\
\cline { 2 - 3 } & Número de trabalhadores & Porcentagem \\
\cline { 2 - 3 } & & \\
\hline Setores tipicamente contratantes & 34.748 .421 & $73,2 \%$ \\
\hline Setores tipicamente terceirizados & & $28,6 \%$ \\
\hline Total & 12.700 .546 & $100 \%$ \\
\hline
\end{tabular}

FONTE: Rais 2013. (DIEESE e CUT, 2014)

NOTA: Setores agregados segundo Class/CNAE 2.0. Não se incluem os setores da agricultura.

O estudo aponta que a terceirização influencia diretamente na distribuição de renda. Em 2013, a remuneração dos trabalhadores terceirizados foi $24,7 \%$ menor do que a concedida aos trabalhadores diretamente contratados. No mesmo ano, 78,5\% dos terceirizados concentravam-se

\footnotetext{
${ }^{7}$ A figura do microempreendedor individual (MEI) foi criada durante o governo Lula pela Lei Complementar n. ${ }^{\circ} 128$, de 19 de dezembro de 2008, e alterada durante o governo Dilma pela Lei Complementar n. ${ }^{\circ} 139$, de 10 de novembro de 2011. Atualmente, podem adotar a forma MEI todos os profissionais das categorias permitidas por lei que faturem até $\mathrm{R} \$ 60.000,00$ (sessenta mil reais) por ano.

A Pesquisa Nacional por Amostra de Domicílios Contínua (PNAD Contínua) sobre o trimestre móvel de junho a agosto de 2015, realizada pelo Instituto Brasileiro de Geografia e Estatística (IBGE), revela que, em relação ao trimestre móvel de junho a agosto de 2015, a taxa de desocupação cresceu 0,6 ponto percentual, passando de $8,1 \%$ para $8,7 \%$. Se comparado com o mesmo trimestre móvel do ano de 2014 , o crescimento é ainda maior, totalizando 1,8 ponto percentual (IBGE, 2015).

Ao mesmo tempo, o número de empregados no setor privado com carteira assinada tem diminuído. Frente ao trimestre móvel de março a maio de 2015, a queda foi de $1,2 \%$, o que representou menos 425 mil pessoas. Já em relação ao mesmo período do ano de 2014, a redução foi de 3,0\%, atingindo cerca de 1,1 milhão de pessoas.

Na contramão desses números, o trabalho por contra própria sofreu um aumento de 4,4\% em relação ao contingente do semestre móvel de junho a agosto de 2014. À primeira vista, a redução do número de postos de trabalho tem proporcionado uma migração de trabalhadores do setor privado com carteira assinada para o trabalho por conta própria.
}

Revista de Direito Brasileira | Florianópolis, SC | v. 23 | n. 9 | p.228-248 |Mai./Ago. 2019 
nas faixas salariais de até três salários mínimos. Enquanto isso, suas jornadas semanais de trabalho foram, em média, três horas maior do que a dos trabalhadores diretos. A taxa de rotatividade também é maior entre os terceirizados. É o que informam as tabelas 2 e 3 :

TABELA 2 - Condições de trabalho e terceirização em 2013

\begin{tabular}{|c|c|c|c|}
\hline Condições de trabalho & $\begin{array}{c}\text { Setores } \\
\text { tipicamente } \\
\text { contratantes }\end{array}$ & $\begin{array}{c}\text { Setores } \\
\text { tipicamente } \\
\text { terceirizados }\end{array}$ & $\begin{array}{c}\text { Diferença } \\
\text { Terceirizados/Contratados }\end{array}$ \\
\hline Remuneração média em Reais (R\$) & 2361,15 & 1776,78 & $-24,7$ \\
\hline Jornada semanal contratada (Horas) & 40 & 43 & 7,5 \\
\hline Tempo de emprego (Anos) & 5,8 & 2,7 & $-53,5$ \\
\hline
\end{tabular}

FONTE: Rais 2013. (DIEESE e CUT, 2014)

NOTA: Setores agregados segundo Class/CNAE 2.0. Não se incluem os setores da agricultura. Remuneração média em dezembro.

TABELA 3 - Distribuição percentual dos trabalhadores contratados diretamente e dos terceirizados por faixa de remuneração

\begin{tabular}{|c|c|c|}
\hline Faixa de remuneração & Setores tipicamente terceirizados & $\begin{array}{c}\text { Diferença Terceirizados/ } \\
\text { Contratados }\end{array}$ \\
\hline Até 2 salários mínimos & 57,1 & 49,3 \\
\hline De 2,01 a 3,00 salários mínimos & 21,4 & 18,1 \\
\hline De 3,01 a 4,00 salários mínimos & & 8,3 \\
\hline De 4 a 7 salários mínimos & 7,8 & 9,5 \\
\hline De 7,01 a 10,0 salários mínimos & 2,4 & 12,4 \\
\hline Acima de 10 salários mínimos & 2,9 & 4,5 \\
\hline Total & 100,0 & 6,1 \\
\hline
\end{tabular}

FONTE: Rais 2013. (DIEESE e CUT, 2014) 
NOTA: Setores agregados segundo Class/CNAE 2.0. Não se incluem os setores

O Instituto de Pesquisa Econômica Aplicada (IPEA) (STEIN et. tal, 2015) também apresentou informações sobre a terceirização no Brasil, utilizando dados da RAIS identificada ${ }^{8}$ de 2007 a 2012. A pesquisa realizada pela instituição indica que a participação da mão de obra terceirizada cresceu 0,1 ponto percentual entre aqueles anos, chegando a 24,5\% do mercado formal de trabalho. Para os pesquisadores (STEIN et. tal, 2015), este percentual permite supor que a estimativa elaborada pela CUT/DIEESE é superestimada.

O estudo ainda demonstra que a disseminação da terceirização é heterogênea, conforme se verifica na tabela a seguir:

TABELA 4 - Serviços considerados para a análise da terceirização e suas participações no emprego formal (Brasil, 2007 a 2012)

\begin{tabular}{|c|c|c|c|c|c|c|}
\hline \multirow{2}{*}{ Serviços } & \multicolumn{2}{|c|}{ 2007 } & \multicolumn{2}{c|}{ 2012 } & Trón \\
\cline { 2 - 7 } & Terceiros & Próprios & $\begin{array}{c}\text { Terceiros } \\
(\%)\end{array}$ & Terceiros & Próprios & $\begin{array}{c}\text { Terces } \\
\text { (\%) }\end{array}$ \\
\hline \multirow{2}{*}{$\begin{array}{c}\text { Montagem e } \\
\text { manutenção de } \\
\text { equipamentos }\end{array}$} & 25.901 & 352.567 & 6,8 & 36.455 & 638.727 & 5,4 \\
\hline $\begin{array}{c}\text { Segurança/ } \\
\text { Vigilância }\end{array}$ & 188.949 & 456.033 & 29,3 & 283.251 & 695.519 & 28,9 \\
\hline $\begin{array}{c}\text { Tecnologia da } \\
\text { Informação }\end{array}$ & 30.916 & 93.244 & 24,9 & 83.919 & 146.270 & 36,5 \\
\hline $\begin{array}{c}\text { Limpeza e } \\
\text { conservação }\end{array}$ & 188.899 & 685.018 & 21,6 & 359.936 & 1.211 .968 & 22,9 \\
\hline $\begin{array}{c}\text { Pesquisa e } \\
\text { desenvolvimento }\end{array}$ & 1.218 & 13.371 & 8,3 & 2.492 & 30.595 & 7,5 \\
\hline $\begin{array}{c}\text { Telemarketing } \\
\text { Total }\end{array}$ & 531.850 & 1.651 .356 & 24,4 & 914.949 & 2.824 .315 & 24,5 \\
\hline
\end{tabular}

FONTE: Rais 2007 - 2012. Elaboração: (STEIN et. tal, 2015)

O IPEA confirma que os trabalhadores terceirizados recebem salários inferiores aos empregados diretos. A diferença chega a 17\%, cai para $12 \%$ quando os pesquisadores controlam a amostragem de acordo com características observáveis e cai novamente para $3 \%$ quando

${ }^{8}$ A RAIS identificada permite o acompanhamento dos mesmos indivíduos ao longo do tempo.

Revista de Direito Brasileira | Florianópolis, SC | v. 23 | n. 9 | p.228-248 |Mai./Ago. 2019 
considerada a diferença média na remuneração de um mesmo indivíduo que muda de emprego e transita da forma de contratação direta para a terceirizada.

Outras pesquisas sobre a terceirização em território nacional trazem dados preocupantes no tocante à violação dos direitos trabalhistas. Segundo Victor Araújo Filgueiras, pesquisador do Centro de Estudos Sindicais e Economia do Trabalho, o trabalho terceirizado e o trabalho análogo ao escravo estão intimamente relacionados. Nos dez maiores flagrantes ocorridos no Brasil entre 2010 e 2013, dos 3.553 (três mil, quinhentos e cinquenta e três) trabalhadores resgatados em situação análoga à escravidão, 2.998 (dois mil, novecentos e noventa e oito) eram terceirizados (FILGUEIRAS, 2014) ${ }^{9}$.

Em diversos setores econômicos, os números indicam a diferença entre a proteção conferida aos prestadores de serviço e aos trabalhadores diretos. Nos setores elétrico e petrolífero, a probabilidade da morte de um prestador de serviços em decorrência de acidentes de trabalho é maior justamente entre os terceirizados. A disparidade pode ser justificada pela intensa delegação das atividades que trazem para a empresa principal a ideia de risco, pela incerteza acerca do agente sobre o qual recai a responsabilidade com a saúde e a segurança dos trabalhadores terceirizados, ou mesmo pelo baixo investimento que das empresas contratadas com os mecanismos que garantam a proteção da saúde e da segurança do trabalhador terceirizado.

$\mathrm{O}$ relatório de Estatísticas de Acidentes do Setor Elétrico Brasileiro, produzido pela Fundação Comitê de Gestão Empresarial (COGE), denunciou que o número de acidentes fatais é, em média, 3,4 vezes maior entre empregados que prestam serviços para distribuidoras, geradoras e transmissoras da área de energia elétrica (DIEESE e CUT, 2014). No ano de 2011, 61 (sessenta e uma) das 79 (setenta e nove) mortes no setor foram de trabalhadores terceirizados

Na última década, poucas têm sido as avaliações de prestígio e de continuidade sobre o desenvolvimento e as tendências da terceirização no Brasil. As efetuadas apresentam problemas metodológicos, dentre os quais, dados quantitativos insuficientes; estimativas indiretas; múltiplos vieses de análise (CAMPOS, 2015).

\section{OS TRABALHADORES NOS PROCESSOS JUDICIAIS: O JUDICIÁRIO COMO LUGAR DE MOBILIZAÇÃO DOS DIREITOS TRABALHISTAS}

O Poder Judiciário não é um campo de pacificação que funciona por mecanismos de input e output, simplesmente oferecendo respostas aos conflitos forjados sob o processo político. Ele detém um papel mais ativo e mais complexo nas disputas políticas por mobilização de direitos.

\footnotetext{
${ }^{9}$ As Convenções n. ${ }^{\circ} 29$ e n. ${ }^{\text {o }} 105$ da Organização Internacional do Trabalho, ambas ratificadas pelo Brasil, dispõem sobre a proibição e sobre a erradicação do trabalho forçado ou obrigatório em todas as suas formas. O artigo 149 do Código Penal tipifica como crime a seguinte conduta: "reduzir alguém a condição análoga à de escravo, quer submetendo-o a trabalhos forçados ou a jornada exaustiva, quer sujeitando-o a condições degradantes de trabalho, quer restringindo, por qualquer meio, sua locomoção em razão de dívida contraída com o empregador ou preposto". Portanto, de acordo com a legislação brasileira, é análogo ao escravo o trabalhador que labora sob condições degradantes, isto é, que violem direitos fundamentais, ameaçando a sua saúde e segurança,ou sob jornadas exaustivas, que impliquem esforço excessivo ou sobrecarga de trabalho. Em 2014, foi aprovado pelo Congresso Nacional o Projeto de Emenda Constitucional n. ${ }^{\circ} 57 / 1999$, que deu nova redação ao artigo 243 da Constituição da República para permitir que as propriedades rurais ou urbanas onde forem localizadas culturas ilícitas de plantas psicotrópicas, ou exploração de trabalho escravo na forma da lei sejam expropriadas e destinadas à reforma agrária ou a programas de habitação popular. De acordo com a, na época, Secretária de Direitos Humanos Ideli Salvatti, a intenção do governo é que a regulamentação da nova emenda inclua apenas os procedimentos adotados para a expropriação dos imóveis, sem alterar o conceito atual de trabalho escravo (NÉRI, 2014). No entanto, sob a justificativa da necessidade de uma definição mais objetiva para o trabalho escravo, tramita na Câmara dos Deputados desde 2012 o Projeto de Lei n. ${ }^{\circ} 3.842$, do exdeputado Moreira Mendes. O candidato a novo texto legal, amplamente apoiado pela bancada ruralista, pretende retirar do Código Penal as expressões "jornada exaustiva" e "condições degradantes de trabalho" e definir trabalho análogo ao de escravo como "todo trabalho ou serviço exigido de uma pessoa sob ameaça, coação ou violência, restringindo sua locomoção e para o qual não se tenha oferecido espontaneamente". O Projeto reduz as hipóteses de configuração do crime e, por isso, tem sido muito criticado pelas entidades que atuam no âmbito do Direito do Trabalho.
}

Revista de Direito Brasileira | Florianópolis, SC | v. 23 | n. 9 | p. 228-248 |Mai./Ago. 2019 
Sem desconsiderar a atuação política direta dos tribunais nas decisões judiciais e na formulação de políticas que outras instituições devem cumprir, Michael McCann (2010) ressalta o seu poder político indireto, isto é, a sua capacidade de configurar o ambiente no qual os usuários defendem interesses. O autor demonstra que a influência do Judiciário sobre a mobilização de direitos é exercida em dois níveis: o "instrumental ou estratégico" e o "nível do poder constitutivo da autoridade judicial"'.

No primeiro, as decisões judiciais configuram o cenário estratégico dos atores sociais. Os indivíduos deliberam e definem o seu modo de agir conforme a percepção que eles têm e as expectativas que criam sobre a atuação do Judiciário.

O campo judicial promove o deslocamento de conflitos da esfera privada para a pública; aumenta a relevância de uma questão, inserindo-a na agenda pública; cria oportunidades para uma parte e constrangimentos para outra; fornece recursos simbólicos de mobilização; influencia posições estratégicas; gera contramobilizações. Enfim, os tribunais "não apenas solucionam pequenas disputas sobre o significado dos direitos, mas também previnem, incitam, estruturam, deslocam e transformam conflitos por toda a sociedade rotineiramente" (MACCANN, 2010, p.185).

O segundo nível de influência reside na construção da vida cultural. A atuação judicial cria formas seletivas de imaginar o real. Ela constrói significados e exclui outros. O legado acumulado pelas ações judiciais ao longo do tempo, uma vez apreendido, internalizado e normalizado pelos cidadãos, influencia na consciência dos sujeitos, refletindo em princípios, valores e lógicas que formam a identidade de um povo.

A atividade jurisdicional sempre foi, portanto, um campo de disputas e um campo em disputa. Um espaço estruturado por relações de força que disputam o "direito de dizer o direito" (BOURDIEU, 2007). Um ambiente, ao mesmo tempo, influenciado por atores que visam compelir o Estado a fazer concessões e influenciador das demandas, das estratégias políticas e, até mesmo, da vida cultural de um povo.

Desde a década de 1970, a atuação política dos tribunais vem intensificando-se. Os juízes passam a ocupar posições tradicionalmente ocupadas por instituições legislativas. Segundo Werneck Vianna et al. (2007), esse processo tem origem nas múltiplas e profundas transformações do período pós Segunda Guerra Mundial: o mesmo período reconhecido por Boaventura de Sousa Santos como marco da fase desorganizada do capitalismo (SANTOS, 1990).

Além da atuação do Tribunal de Nuremberg, que sobrepujou as fronteiras estatais, os anos seguintes à guerra foram marcados pelo surgimento de Constituições cujo "núcleo dogmático" induzia o poder soberano a atuar de acordo com determinados valores tidos por fundamentais. $\mathrm{O}$ Constitucionalismo democrático, que acompanhou a fase organizada do capitalismo (SANTOS, 1990), tentava regular o futuro a partir do tempo presente ${ }^{10}$. Criavam-se normas abertas, programáticas e completamente distintas da ortodoxia liberal.

Com a mitigação do Welfare e a prevalência da ideologia neoliberal, que marcaram o início da fase desorganizada do capitalismo, o sentimento de certeza desapareceu. Pouco a pouco, desfez-se a crença de que o Direito era capaz de regular todos os aspectos da vida social e surgiu a nova crença de que o sistema jurídico era incapaz de acompanhar e, até mesmo, atrasava os novos processos de flexibilização, sempre associados à modernidade e ao progresso. O retraimento do Direito e o descrédito das instituições tradicionalmente políticas levaram os cidadãos a lançarem suas expectativas de justiça para o núcleo ainda reputado como guardião da lei: o Poder Judiciário. Com o crescimento da litigação, o acesso à justiça passou a integrar o topo das agendas de políticas públicas.

\footnotetext{
${ }^{10}$ Segundo a Teoria do Risco de Raffaele De Giorgi (1994), na vã tentativa de controlar o não-saber futuro, o Direito constrói o que entende por risco e os meios pelos quais se julga capaz de evitá-los, mas, ao fazer isso, o sistema cria novos riscos. Não há qualquer segurança na idéia de segurança.
}

Revista de Direito Brasileira | Florianópolis, SC | v. 23 | n. 9 | p.228-248 |Mai./Ago. 2019 
Medidas de política judiciária, tais como a criação de juizados de pequenas causas e a institucionalização das classactions, generalizam-se, fortalecendo a atuação do juiz na tomada de decisão em matéria de políticas públicas. O juiz passa a ser o protagonista da questão social. Como afirma Werneck Vianna et. al. (2007), "o cidadão volta-se para ele, mobilizando o arsenal de recursos criado pelo legislador a fim de lhe proporcionar vias alternativas para a defesa e eventuais conquistas de direitos". Em uma espécie de memória das origens escolásticas da autoridade, invocam-se agentes externos à relação de trabalho a quem foram outorgados o saber e o poder.

A terceirização é uma das áreas representativas da expansão da atuação política direta e indireta dos tribunais. A configuração das decisões da Justiça do Trabalho nos dissídios individuais e coletivos influencia as estratégias adotadas pelos trabalhadores terceirizados e pelos empresários na luta pela mobilização de direitos. À medida que as decisões ressaltam determinadas questões e ignoram outras, são construídos os significados e as expectativas através dos quais os atores do local de trabalho fissurado vão operar.

Em 2014, o Supremo Tribunal Federal deu maior atenção ao tema. O Ministro Luiz Fux reconheceu a repercussão geral da discussão sobre a delegação de atividades fins no Recurso Extraordinário com Agravo n. ${ }^{\circ} 713.211$ interposto no curso da ação civil pública proposta pelo Ministério Público do Trabalho da $3^{\text {a }}$ Região em face da Celulose Nipo Brasileira S/A - CENIBRA. Logo depois, o Ministro Teori Zavascki também reconheceu a repercussão geral da matéria no julgamento do Recurso Extraordinário com Agravo n. ${ }^{\circ}$ 791.932, interposto pela empresa Contax S.A. em ação que questiona a terceirização de serviços de contact center.

Mas o desempenho político da Justiça vai além das decisões judiciais. O Tribunal Superior do Trabalho fixou os próprios limites para a delegação de atividades a terceiros e para as relações trabalhistas dela decorrentes no Enunciado n. ${ }^{\circ} 256$ e, posteriormente, na Súmula n. ${ }^{\circ 331}$. Além disso, promoveu uma audiência pública para debater o tema em 2011. No evento, foi articulada a criação do Fórum Nacional Permanente em Defesa dos Direitos dos Trabalhadores Ameaçados pela Terceirização, composto por diversas instituições e profissionais ligados ao mundo do trabalho. Os magistrados ainda têm atuado de forma enfática no trâmite do Projeto de Lei n. $^{\circ}$ 4.330/2004 através da sua entidade representativa, a Associação Nacional dos Magistrados do Trabalho.

Há dois fatores que parecem favorecer a ampliação da interferência dos tribunais em se tratando de terceirização. O primeiro deles é a demora na produção de um marco normativo específico. Enquanto o Poder Legislativo está preso às questões políticas e às disputas de poder que lhes são próprias, é o Judiciário quem assume o papel de fixar as políticas referentes a matérias controvertidas (WERNECK VIANNA, 1999). Dada a falta de definição legislativa, a terceirização foi incluída na agenda judicial e recebeu a chancela estatal sob as condições estabelecidas na Súmula n. ${ }^{\circ} 331$.

Embora operem simultaneamente, os sistema político, jurídico e econômico detêm temporalidades e técnicas de temporalização distintas. Interpretando as novas estratégias empresariais, o sistema político criou leis que permitiam a fissuração, mas não a regulavam. $\mathrm{O}$ vácuo normativo foi construído como instabilidade dentro da esfera jurídica, que tinha de usar a distinção entre lícito e ilícito sem parâmetros legais específicos. A instabilidade jurídica, por sua vez, foi interpretada como gastos pelo sistema econômico e como disputas de poder pelo sistema político.Uma vez que o Poder Legislativo estava centrado nos diversos jogos de poder, foi o Poder Judiciário o primeiro a estabelecer parâmetros normativos para a fissuração através das suas decisões judiciais e da edição de súmulas. As normas tornaram-se legítimas à medida que passaram pelos procedimentos do Judiciário.

O segundo fator é a falta, ou a impossibilidade ${ }^{11}$ da garantia de efetividade das normas trabalhistas existentes. A criação de normas regulamentadoras não implica a sua observância. E a

\footnotetext{
${ }^{11}$ Aqui, cabe a crítica que o professor Raffaele De Giorgi (2011, p.10-11) faz sobre a ausência de sentido na distinção entre validade e eficácia, já enunciada no capítulo anterior. A validade não consegue impor causas objetivas ao agir e

Revista de Direito Brasileira | Florianópolis, SC | v. 23 | n. 9 | p. 228-248 |Mai./Ago. 2019
} 
inobservância leva os trabalhadores aos tribunais na tentativa de que o Estado use a sua força para impor condutas aos empregadores.

No entanto, os usuários deparam-se com dificuldades para acessar o Judiciário, com lacunas no processo de democratização da estrutura judiciária, com o excesso de demandas e com a longa duração processual. Inclusive, esta última é um dos principais incentivos para que os trabalhadores optem pela conciliação do conflito, deixando de receber a integralidade dos montantes que lhe caberiam.

Adalberto Cardoso e Telma Lage (2007) defendem que o aumento do número de demandas na Justiça do Trabalho brasileira está diretamente ligado ao modelo de disciplina das relações trabalhistas, cujas características contribuem para a sua própria deslegitimação. Os empresários realizam um cálculo de custo e benefício e chegam à conclusão de que os possíveis gastos com a condenação judicial são mais compensadores do que o cumprimento da legislação trabalhista:

[...] [Há] polos na relação de trabalho inteiramente extrínseca à regulação estatal, de um lado, e na adesão sem mais à norma por parte de empresários (digamos) kantianos, de outro. Em algum lugar entre estes polos, encontraremos o capitalista médio e o trabalhador médio, expressões ou personificações de seu lugar na distribuição de recursos materiais e de poder, ambos atuando para fazer valer a norma em seu favor, ou, no caso dos capitalistas, para que a norma não seja aplicada. A diferença entre ambos é que, para evadir-se da norma, basta ao capitalista não assinar a carteira de trabalho de um ou mais de seus funcionários, e este será um ato administrativo imediato, cujos custos podem ou não lhe ser cobrados num futuro indeterminado. Os trabalhadores, para fazer valer a norma burlada, isto é, para cobrar do capitalista esses custos, dependem de três coisas: sua capacidade de ação coletiva; a ação do órgão fiscal do Estado; do Ministério Público do Trabalho; ou a Justiça do Trabalho. (CARDOSO e LAGE, 2007, p.56)

Os autores também chegam a essa conclusão pesquisando as limitações do modelo de inspeção do trabalho no Brasil (Cardoso e Lage, 2005). Eles reconhecem que, desde a ratificação da Convenção n. ${ }^{\circ} 81$ da Organização Internacional do Trabalho, que versa sobre a inspeção do trabalho na indústria e no comércio, o país aprimorou as instituições de fiscalização, adotou um sistema informatizado de controle, alterou os trâmites burocráticos e passou a treinar os fiscais do trabalho. No entanto, a despeito do progresso na área, a inspeção ainda atinge uma fração muito pequena dos potenciais destinatários, além de contar com um número deficiente de fiscais e com uma taxa pequena de regularização de vínculos empregatícios por parte das grandes empresas, já que essas esgotam os artifícios legais para retardar a solução dos processos administrativos e judiciais.

De fato, as estatísticas do Tribunal Superior do Trabalho indicam que os processos sobre terceirização vêm aumentando, especialmente os que questionam a responsabilidade pelas obrigações trabalhistas. Na lista dos cem assuntos mais recorrentes em casos novos julgados pelas Varas do Trabalho, a responsabilidade em casos de terceirização ocupa o trigésimo nono lugar, com 65.647 (sessenta e cinco mil, seiscentos e quarenta e sete) processos. Nos Tribunais Regionais do Trabalho, o tema ocupa a trigésima quarta posição, com 18.607 (dezoito mil, seiscentos e sete processos). Já no TST, a matéria ocupa o sétimo lugar, com 12.184 (doze mil, cento e oitenta e quatro) processos, mas é imediatamente precedida pela responsabilidade em caso de terceirização por ente público, que conta com um total de 14.576 (quatorze mil, quinhentos e setenta e seis) processos.

apenas fixa a possibilidade de ser diferente do que é. A eficácia, por sua vez, esconde as inúmeras possibilidades de ser diferente do que foi construído como dever ser e traz consigo a idéia de que o Direito aplica-se a uma realidade externa, quandoé ele quem constrói a própria realidade fundada no dever ser e no binômio lícito e ilícito.

Revista de Direito Brasileira | Florianópolis, SC | v. 23 | n. 9 | p.228-248 |Mai./Ago. 2019 


\section{CONSIDERAÇÕES FINAIS}

Se a constitucionalização foi a tentativa de conferir previsibilidade às relações trabalhistas, na era do capitalismo desorganizado, marcada pela reestruturação empresarial e trabalhista, ela se torna insuficiente para garantir ao trabalhador o exercícioda sua cidadania. Neste contexto, o Poder Judiciário surge como um ator de políticas diretas e indiretas. Suas respostas configuram o cenário no qual os trabalhadores mobilizam o seu direito. Elas influenciam na construção de estratégias, limitando ou ampliando possibilidades de mobilização. O Judiciário é, ao mesmo tempo, um campo de disputas e um campo em disputa.

A atuação política dos tribunais é facilmente observada quando a terceirização é o objeto em debate. O Poder Judiciário criou os primeiros limites específicos à delegação de serviços com o Enunciado n. ${ }^{\circ}$ 256, que a proibia e, em seguida, com a Súmula n. ${ }^{\circ} 331$, que permitia apenas a terceirização das chamadas atividades meio. O Tribunal Superior do Trabalho ainda promoveu uma audiência pública sobre o tema e os membros do Judiciário participaram ativamente dos debates na Câmara dos Deputados acerca do Projeto de Lei n. ${ }^{\circ}$ 4.330/2004.

Além disso, a soma das decisões em matéria de terceirização auxilia tanto na construção do ambiente em que os trabalhadores buscam o direito de dizer o que é o direito quanto na composição da cultura do local de trabalho nacional. As pesquisas mostram que o número de ações relacionadas à delegação de atividades tem aumentado. Esses dados podem ser explicados por, pelo menos, dois fatores: o silêncio duradouro do poder Legislativo em regular a matéria e a já mencionada falta de efetividade dos direitos trabalhistas no país, ainda que inseridos no texto constitucional.

Os trabalhadores também são peças na engrenagem do sistema fragmentado. O local de trabalho inclui-lhes formalmente como elementos essenciais para a produção, mas a virtualização dos vínculos nega-lhes o exercício pleno da cidadania e da integração social. Os empregados fissurados transitam constantemente entre a inclusão e a exclusão.

O aumento da atuação dos tribunais indica que, em tempos de instabilidade, a noção de cidadania pelo trabalho deve ser alargada para além do aspecto puramente estatutário, porque este já não é capaz de assegurá-la. Segundo Marshall (1967), o exercício dos direitos sociais de cidadania $^{12}$ está diretamente ligado à ideia da igualdade. Esta, por sua vez, materializa-se em direitos civis e políticos, cujo exercício enriquece o conteúdo da cidadania e da noção de igualdade que ele comporta. Portanto, as possibilidades da ação cidadã são construídas de modo circular e por intermédio de um abastecimento constante: a efetividade da igualdade e dos direitos civis e políticos a ela relacionados conduz ao enriquecimento da cidadania e dos direitos sociais a ela ligados e vice-versa.

No campo jurídico, para fomentar este processo, não basta a simples regulamentação da terceirização. É essencial que o Direito do Trabalho encontre novos caminhos entre a estagnação como único meio de proteção do trabalhador e a flexibilização em nome de um progresso abstrato e irrealizável. No entanto, o Direito, que constrói a realidade a partir da lógica binária entre lícito e ilícito, não é capaz de garantir a efetividade das suas próprias disposições. Ele é apenas uma técnica de projeção do não saber futuro.

No sistema político, é preciso incentivar a participação política do trabalhador por intermédio da politização dos espaços de produção (SANTOS, B. S., 1997), um processo multidimensional de identificação das relações de poder que permeiam o local de trabalho

\footnotetext{
${ }^{12}$ Segundo Theodore H. Marshall (1967, p. 149-153), os direitos sociais de cidadaniaconstituem um direito absoluto a determinado padrão de civilização que é condicional apenas à contrapartida de obrigações gerais da cidadania. Seu conteúdo inclui desde o bem-estar e segurança econômicos até o direito de compartilhar uma herança social e de viver a vida de um ser civilizado de acordo com os padrões prevalentes na sociedade.
}

Revista de Direito Brasileira | Florianópolis, SC | v. 23 | n. 9 | p. 228-248 |Mai./Ago. 2019 
fissurado. Pelo mesmo motivo, deve-se democratizar não somente o acesso à Justiça, como também a própria estrutura do Poder Judiciário, tendo em vista a sua relevância tanto na composição do ambiente no qual os atores buscam o poder de dizer o direito do trabalho quanto na construção da vida cultural e da identidade do trabalhador brasileiro.

Somente através do efetivo exercício da cidadania, o trabalhador deixa de ser um simples produto do local de trabalho instável e precarizado para converter-se em agente de determinação do destino individual e coletivo.

\section{REFERÊNCIAS BIBLIOGRÁFICAS}

BACKES, Ana Luiza; AZEVEDO, Débora Bithiah de (org.). A sociedade no Parlamento Imagens da Assembleia Nacional Constituinte de 1987/1988. Brasília: Câmara dos Deputados, Edições Câmara, 2008.

BOURDIEU, Pierre. A economia das trocas linguísticas. São Paulo: Edusp, 2008.

BRANDÃO, Lucas Coelho. Os movimentos sociais e a Assembleia Nacional Constituinte de 1987-1988: entre a política institucional e a participação popu87lar. Dissertação de Mestrado. São Paulo: Faculdade de Filosofia, Letras e Ciências Humanas da USP, 2011.

BRASIL. Anais da Assembleia Nacional Constituinte. Brasília: Senado Federal, 1988a. Disponível em <http://www.senado.gov.br/publicacoes/anais/asp/CT_Abertura.asp>. Acesso em 17 de mai. de 2018.

Base de Sugestão dos Constituintes (SGCO). Brasília: Câmara dos Deputados, 1987a. Disponível em: <http://www2.camara.leg.br/atividadelegislativa/legislacao/Constituicoes_Brasileiras/constituicao-cidada/o-processoconstituinte/sugestoes-dos-constituintes>. Acesso em 17 de mai. de 2018.

Conselho Nacional de Justiça. Justiça em números 2015 (ano-base 2014). Disponível em: <http://www.cnj.jus.br/programas-e-acoes/pj-justica-em-numeros〉. Acesso em 11 de jun. de 2018 .

. Constituição da República Federativa do Brasil. Brasília: Senado, 1988b. Disponível em <http://www.planalto.gov.br/ccivil_03/constituicao/constituicaocompilado.htm>. Acesso em 08 de mai. de 2018.

Emenda Constitucional $\mathbf{n}^{\mathbf{0}}$ 26, de 27 de novembro de 1985. Convoca Assembleia Nacional Constituinte e dá outras providências. Disponível em <http://www.planalto.gov.br/ccivil_03/Constituicao/Emendas/Emc_anterior1988/emc2685.htm>. Acesso em 21 de mai. de 2018.

.Emendas Populares encaminhadas à Assembleia Nacional Constituinte. Câmara dos Deputados, 1987b. Disponível em <http://www2.camara.leg.br/atividadelegislativa/legislacao/Constituicoes_Brasileiras/constituicao-cidada/o-processoconstituinte/comissao-de-sistematizacao/emendas-de-plenario-e-populares $>$. Acesso em $21 \mathrm{de}$ mai. de 2018.

Regimento Interno da Assembleia Nacional Constituinte. Brasília: Câmara dos Deputados, 1987c. Disponível em <http://www2.camara.leg.br/atividadelegislativa/legislacao/Constituicoes_Brasileiras/constituicaocidada/publicacoes/regimento_interno_anc>. Acesso em 21 de mai. de 2018. 
.Sistema de Apoio Informático à Constituinte (SAIC). Brasília: Senado Federal, 1987d. Disponível em: <http://www.senado.gov.br/atividade/baseshist/bh.asp\#/>. Acesso em 21 de mai. de 2018.

. Tribunal Superior do Trabalho. Coordenadoria de Estatística e Pesquisa. Lista das 100 pessoas jurídicas com maior número de processos com débitos trabalhistas na Justiça do Trabalho. 19 jun. 2012. Disponível em:<http://www.tst.jus.br/documents/10157/070672fb-8d294b04-a20f-6edb244c2807>. Acesso em 05 de mai. de 2018.

Tribunal Superior do Trabalho. Relatório Geral da Justiça do Trabalho 2014.

Disponível em: <http://www.tst.jus.br/documents/10157/887f0a39-0471-45da-9bd51fcc72ab3a1b>. Acesso em 05 de mai. de 2018.

MICHILES, Carlos [et al.]. Cidadão constituinte: a saga das emendas populares. RJ: Paz e Terra, 1989.

CARDOSO, Adalberto Moreira; LAGE, Telma. As normas e os fatos: desenho e efetividade das instituições de regulação do mercado de trabalho no Brasil. Rio de Janeiro: Editora FGC, 2007.

A inspeção do trabalho no Brasil. Dados - Revista de Ciências Sociais, v.48, n.3, p.451-490, jul/set 2005.

CARELLI, Rodrigo de Lacerda. Terceirização e intermediação de mão-de-obra: ruptura do sistema trabalhista, precarização do trabalho e exclusão social. Rio de Janeiro: Renovar, 2003.

. Formas atípicas de trabalho. São Paulo: LTr, 2004.

DE GIORGI, Raffaele. A investigação sociológica do Direito na Teoria dos Sistemas. Palestra proferida no II Congresso da Associação Brasileira dos Pesquisadores em Sociologia do Direito. Porto Alegre- RS. 26 de outubro de 2011. jun.1994.

. O risco na sociedade contemporânea. Sequência, Florianópolis, v.15, n.28, p.45-54,

DIEESE (Departamento Intersindical de Estatísticas e Estudos Socioeconômicos). O processo de terceirização e seus efeitos sobre os trabalhadores no Brasil. 2007. Disponível em: <http://ftp.medicina.ufmg.br/osat/arquivos/6-07082015.pdf>. Acesso em 20 de mai. de 2018.

. O emprego no setor de telecomunicações dez anos após a privatização. Estudos e pesquisas, n.46, jul. 2009. Disponível em: <http://www.dieese.

org.br/estudosepesquisas/2009/estPesq46PrivatizacaoTelecomunicacoes.pdf $>$. Acesso em 20 de jun. de 2018.

DIEESE (Departamento Intersindical de Estatísticas e Estudos Socioeconômicos); CUT (Central Única dos Trabalhadores). Tercerização e desenvolvimento: uma conta que não fecha. 2014. Disponível em: <http://www.cut.org.br/system/uploads/ck/files/Dossie-TerceirizaçaoeDesenvolvimentolayout.pdf>. Acesso em 20 de jun. de 2018.

DRUCK, Maria da Graça; FRANCO, Tânia (Org.). A perda da razão social do trabalho:terceirização e precarização. São Paulo: Boitempo Editorial, 2007. . A terceirização no Brasil: novo e velho fenômeno. Laboreal, v.4, n. 2, p.83-94, 2008. 
DRUCK, Maria da Graça; THÉBAUD-MONY, Annie. Terceirização: a erosão dos direitos dos trabalhadores na França e no Brasil. In: DRUCK, Graça; FRANCO, Tânia. (Org.). A perda da razão social do trabalho: terceirização e precarização. São Paulo: Boitempo, 2007.

FILGUEIRAS, Vitor Araújo. Terceirização e trabalho escravo: coincidência? Repórter Brasil, 24 jun. 2014. Disponível em: <http://reporterbrasil.org.br/2014/06/terceirizacao-e-trabalhoanalogo-ao-escravo-coincidencia/> . Acesso em 22 de mai. de 2018.

FONTANELLA, Denise; TEVARES, Eveline; LEIRIA, Jerônimo. S. O lado (des)humano da terceirização: o impacto da terceirização nas empresas, nas pessoas e como administrá-lo. Salvador: Casa da Qualidade, 1994.

FGV (Fundação Getúlio Vargas). Relatório do ICJ Brasil. $1^{\circ}$ Trimestre de 2014 ao $4^{\circ}$ Trimestre de 2014. Ano 06. Disponível em: <http://bibliotecadigital.fgv.br/ dspace/bitstream/handle/10438/14089/Relat\%C3\%B3rio\%20ICJBrasil\%20-\%20ano\%206.pdf ?sequence $=1 \&$ is Allowed=y $>$. Acesso em 22 de mai. de 2018.

IBGE (Instituto Brasileiro de Geografia e Estatística). Pesquisa Nacional por Amostra de Domicílios Contínua. Agosto de 2015. Disponível em: <http:ftp://ftp.ibge.gov.br/Trabalho_e_ Rendimento/Pesquisa_Nacional_por_Amostra_de_Domicilios_continua/Mensal/Comentarios/pn adc_201508_comentarios.pdf>. Acesso em 20 de mai. de 2018.

. Comissão Nacional de Classificação. Disponível em:<http://www.cnae.ibge.gov.br/> . Acesso em 25 de mai. de 2018.

LEIRIA, Jerônimo S. Terceirização: uma alternativa de flexibilidade empresarial. 5 ed. Porto Alegre: DC Luzzatto, 1992.

MADEIRA FILHO, Wilson; CALLEGARI, José Antonio. "Formação do espírito científico intersdisciplinar: a produção solidária do conhecimento". In:Confluências. Vol. 12, n.1. Niterói: PPGSD-UFF, outubro de 2012.

MARSHALL, Thomas Humphrey. Cidadania, classe social e status. Rio de Janeiro: Zahar Editores, 1967.

MCCANN, Michael W. Poder Judiciário e mobilização do direito: uma perspectiva dos 'usuários'. Revista da EMARF, Cadernos Temáticos, Rio de Janeiro, p.175-196, dezembro de 2010. Disponível em: <http://www.trf2.gov.br/emarf/documents/revistaemarfseminario.pdf\#page $=176>$. Acesso em 14 de jun. de 2018 .

MINTZBERG, Henry; QUINN, James Brian. O processo da estratégia. 3 ed. Porto Alegre: Bookman, 2011.

NÉRI, Felipe. Congresso Nacional promulga a PEC do trabalho escravo. G1, Brasília, 05 jun. 2014. Disponível em: <http://g1.globo.com/politica/noticia/2014/06/congresso-nacional promulga-pec-do-trabalho-escravo.html>. Acesso em 21 de mai. de 2018.

PILATTI, Adriano. Constituinte de 1987-1988. Progressistas, Conservadores, Ordem Econômica e Regras do Jogo. RJ: Lúmen Júris, 2008.

POCHMANN, Márcio. Terceirização desregulada e seus efeitos no mercado de trabalho no Brasil. Revista do TST, Brasília, v.80, n.3, p.215-227, jul./set. 2014. 
RAMOS, Dora Maria de Oliveira. Terceirização na Administração Pública. São Paulo: LTr, 2001.

RATTES, Anna Maria. "Um olhar de vinte anos”. In: Constituição 20 Anos: Estado, Democracia e Participação Popular. Caderno de Textos. Brasília: Câmara dos Deputados, 2009.

SANTOS, Boaventura de Sousa. O Estado e o Direito na transição pós-moderna:para um novo senso comum sobre o poder e o Direito. Revista Crítica de Ciências Sociais, Coimbra, n.30, jun.1990.

Cortez, 2009.

A crítica da razão indolente. Contra o desperdício da experiência. São Paulo:

SECCHI, Leonardo. Políticas públicas:conceitos, esquemas de análises, casos práticos. São Paulo: CENGAGE Learning, 2012.

SILVA, Ciro Pereira. A terceirização responsável: modernidade e modismo. São Paulo: LTr, 1997.

STEIN, Mariano; et al. (Coords.). The politics of policies. Economic and social progress in Latin America. Washington: Banco Interamericano de Desenvolvimento, 2006.

STEIN, Guilherme; ZYLBERSTAJN, Hélio; ZYLBERSTAJN, Eduardo. Terceirização e salários In: IPEA (Instituto de Pesquisa Econômica aplicada). Mercado de trabalho: conjuntura e análise, ano 21, n. 59, p.27-34, out. 2015.

WERNECK VIANNA, Luiz. A judicialização da política e das relações sociais no Brasil. Rio de Janeiro: Editora Revan, 1999.

WERNECK VIANNA, Luiz; BURGOS, Marcelo Baumann; SALLES, Paula Martins. Dezessete anos de judicialização da política. Revista Tempo Social, São Paulo, v.19, n.2, p.39-85, nov. 2007. 